\title{
Can the increase in body mass index explain the rising trend in asthma in children?
}

\author{
S Chinn, R J Rona
}

\begin{abstract}
Background-The reported association between asthma and obesity and the documented rise in each over time have led to suggestions that rising obesity might explain the increase in the prevalence of asthma. Trends in both in British children participating in the National Study of Health and Growth were marked from 1982 to 1994.

Methods-Odd ratios for trends in asthma and symptoms in 8 and 9 year old children were calculated with and without adjustment for body mass index (BMI).

Results-In a representative sample of white children the odds ratio per year for asthma was $1.09(95 \%$ CI 1.07 to 1.11$)$ before and after adjustment for BMI for boys and $1.09(95 \%$ CI 1.07 to 1.12$)$ and 1.09 (95\% CI 1.05 to 1.12$)$, respectively, for girls. Unadjusted and adjusted odds ratios were also virtually identical for wheeze and "asthma or bronchitis". The lack of effect of adjustment was due to a change in the association between BMI and symptoms with time.

Conclusions-Trends in overweight and obesity do not explain the increase in asthma. The evidence points towards the association between asthma and obesity being of recent origin. This may be explained by obesity being a marker of recent lifestyle differences now associated with both asthma and overweight.

(Thorax 2001;56:845-850)
\end{abstract}

Keywords: asthma; obesity; body mass index; trend

There has been a recent increase in interest in the association between asthma and obesity. Positive associations have been reported between asthma and body mass index (BMI) in young adult women in Britain, ${ }^{1}$ in female adolescents and adults in Canada, ${ }^{2}$ and in Black and Hispanic children in the United States. ${ }^{3}$ Some support for this being a causal link is provided by longitudinal studies in which weight gain preceded an increased onset of asthma in women and in girls, ${ }^{56}$ and a randomised controlled trial of weight reduction in obese subjects with asthma. ${ }^{7}$

It has been suggested that increases in obesity may have contributed to the rise in asthma. $^{568}$ Increases in asthma ${ }^{9-12}$ and in weight-for-height or obesity ${ }^{1314}$ have been reported in children in Britain over the past 20 years. The National Study of Health and Growth (NSHG) was unique in collecting standardised information in children on asthma symptoms, height, weight, and subcutaneous fat over a long period of time. In a recent report the study found an association between BMI and asthma and persistent wheeze in a representative sample of white children aged 4-11 years and in girls in a multiethnic inner city sample. ${ }^{15}$ In this paper we report on the evidence from the NSHG as to whether the increase in BMI contributed to the rise in asthma in children. As asthma symptoms have been reported to be associated with family size or birth order in some studies ${ }^{16}{ }^{17}$ and with low birth weight ${ }^{118}$ or greater birth weight, ${ }^{19}$ we also examined the potential of these variables as alternative confounding or additional factors for explaining the trend in asthma.

\section{Methods}

SUBJECTS

The NSHG was a mixed longitudinal study of primary school children from 1972 to 1994 in England and Scotland. In 1972, 22 employment exchange areas in England and six in Scotland were selected by stratified random sampling, with weighting towards poorer areas, and state primary schools were selected to provide at least 300 children aged 5-11 years in each area. In 1983 a new sample of English inner city areas was selected ${ }^{20}$ because, despite the weighting, the social class distribution of the English sample was found to be close to that for England and Wales ${ }^{21}$ and an additional eight Scottish areas were selected as the original sample was too small for most purposes. These areas were surveyed in odd years from 1983 to 1993 . The original 22 English areas and the 14 Scottish areas are termed the representative sample. For simplicity, the combined 1983/4 Scottish areas and the 1984 English areas are referred to as the 1984 sample, and similarly for subsequent years.

At each survey children were classified by the field worker into ethnic origin groups and, for the inner city sample, the language spoken at home was recorded by the school. Data for the few non-white children in the representative sample were omitted from analyses. Otherwise, all eligible children with data were included as specified in the details of each analysis. Children in the inner city sample were grouped into four ethnic origin categories: white, African-Caribbean, Indian subcontinent, and other. Cohort age was defined as the difference between the year of survey and the year of birth.

\section{MEASUREMENTS}

All children were measured and weighed unless the child's parents refused. Height was measured on a specially designed stadiometer
July 2001 fopted for publication

25 July 2001 


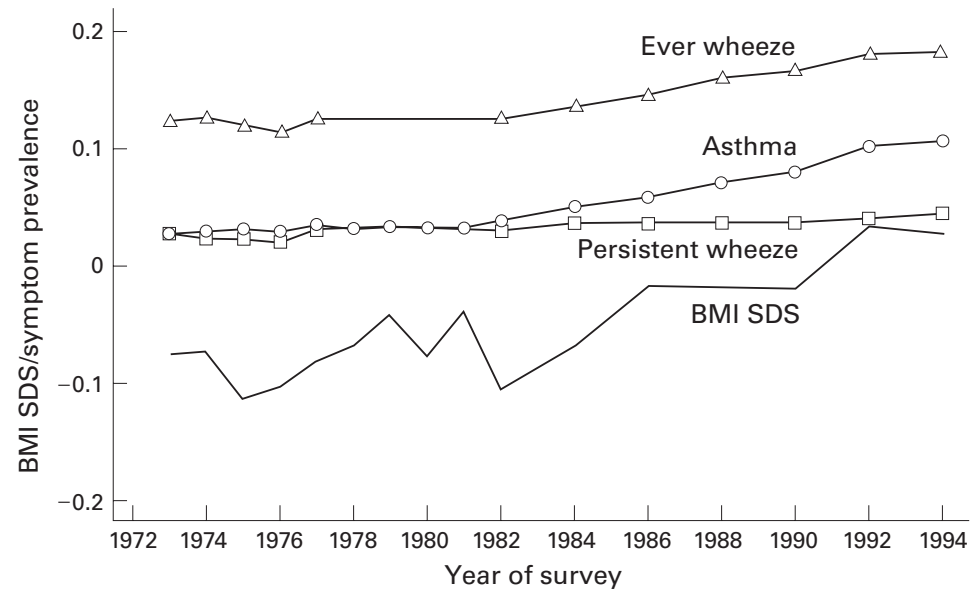

Figure 1 Trends in the prevalence of asthma, ever wheeze, persistent wheeze, and BMI $S D S$ in white boys in the representative sample.

(Holtain) using the method described by Tanner et $a .^{22}$ Height was recorded to the last $0.5 \mathrm{~cm}$ from 1972 to 1976 , and to $0.1 \mathrm{~cm}$ from $1977 ; 0.25$ or $0.05 \mathrm{~cm}$ was added as appropriate to correct the bias. Children were weighed in underpants, with weight recorded to the last complete $100 \mathrm{~g}$. The standard deviation score (SDS) for BMI was calculated from the UK 1990 reference curves. ${ }^{23}$ Cut off points for overweight and obesity were defined as the SDS corresponding to BMI 25 and 30, respectively, at age 19.5 years, and the limit for underweight was defined similarly to correspond to BMI 20.

Triceps skinfold thickness was measured as recommended by Tanner and Whitehouse except that the mid point between the tip of the acromion and olecranon was marked with the arm hanging straight instead of bent. ${ }^{24}$ Triceps skinfold SDS was calculated using the NSHG 1990 data for white English children as this sample formed the majority of the data for 5-11 year olds used to calculate the national reference curves. ${ }^{25}$

\section{QUESTIONNAIRE DATA}

Other data were collected by a selfadministered questionnaire sent to the parent or guardian, normally completed by the child's mother. The total time period for which data on asthma were available was 1973-94, with a reduced sample including few 5 year old children from 1973 to 1976.

The respiratory questions analysed were: "Has he or she suffered from either of the following illnesses in the last 12 months? Asthma: If yes, how many attacks has he or she had in the last 12 months?" and a similar question for bronchitis: "Does his or her chest ever sound wheezy or whistling? If you answered yes, does he or she get this on most days or nights?" Positive answers to the last two questions are referred to as "ever wheeze" and "persistent wheeze". The questions on asthma and bronchitis were asked in all years from 1973 to 1994. A child was considered to have asthma if at least one attack had occurred during the year. The questions on wheeze were asked from 1973 to 1977 , and from 1982 to 1994 .
Birth weight was requested at entry to the study. Length of gestation was collected from 1977 to 1994 , and birth weight was internally standardised by sex and ethnic group to the mean for non-multiple births for gestational age using the method of Bland et al. ${ }^{26}$ This birth weight SDS was then categorised according to the SDS corresponding to the categories $<2500$ g, 2500-<3000 g, 3000-<3500 g, and $3500+\mathrm{g}$ at 40 weeks gestation for white children - that is, a similar procedure to that for the definitions of under and overweight. The total number of siblings and number of older siblings were recorded at each survey. Whether the mother smoked in pregnancy with the child was asked in 1982 and from 1987 to 1994 , and information on the total number of cigarettes smoked per day was also available for these surveys. To maximise the data available and minimise the recall time for the mother, the earliest information for each child was analysed.

\section{DATA ANALYSIS}

Trends in asthma symptoms and BMI SDS were examined graphically for the period of availability of the data.

The primary aim of this paper was to examine the potential of BMI to explain the increasing prevalence of asthma. A single observation for each child was selected by restricting the data at each survey to the cohorts reaching the age of 8 or 9 years from 1982 to 1994 for the representative sample and from 1983 to 1993 for the inner city sample. This age group was chosen as pubertal events would have minimal impact at that age and BMI increased more in children aged 8 years or over than in those aged 7 or less. ${ }^{13}$ Logistic regression was used to calculate trends in asthma and/or bronchitis, ever wheeze, persistent wheeze, and cough which were expressed as odds ratio per year. ${ }^{27}$ Adjusted odds ratios were calculated on adding BMI SDS or category to the model. The effect of including triceps skinfold SDS, family size and birth weight, with and without adjustment for length of gestation, was also studied. Parental smoking was analysed in addition from 1987 to 1994.

The possibility that the relation of asthma to BMI had changed over time was investigated in the representative samples by testing the interaction of year of survey and BMI SDS on outcome variables using 1982 and 1994 data from children across the full age range of the study, and across all years in the selected cohorts.

Finally, as longitudinal data were available, the incidence was examined in relation to BMI by linking data for children at cohort age 5 or 6 years with that collected 4 years later. Asthma at cohort age 9 or 10 was analysed by BMI group in children who were not reported to have asthma at the age of 5 or 6 . Similar analyses were performed in relation to "ever wheeze".

\section{Results}

The response rate to measurement exceeded $94 \%$ in all years and in each sample, except in the inner city sample in 1993 when it was $91 \%$. 
Table 1 Trends in potential explanatory variables from 1982 to 1994 in the representative sample children aged 8 or 9 years ${ }^{\star}$ with information on symptoms

\begin{tabular}{lll}
\hline Variable & Boys & Girls \\
\cline { 2 - 3 } & \multicolumn{1}{c}{ Linear increase per year $(95 \%$ confidence interval) } \\
\hline Body mass index SDS & $0.011(0.006$ to 0.016$)$ & $0.009(0.014$ to 0.024$)$ \\
Triceps skinfold SDS & $0.012(0.007$ to 0.016$)$ & $0.008(0.003$ to 0.013$)$ \\
Birth weight $(\mathrm{g})$ & $0.78(-3.70$ to 2.18$)$ & $2.75(-0.19$ to 5.69$)$ \\
Birth weight for gestational age SDS & $0.001(-0.005$ to 0.007$)$ & $0.010(0.004$ to 0.006$)$ \\
Number of older siblings & $0.01(0.01$ to 0.02$)$ & $0.01(0.00$ to 0.02$)$ \\
Total number of siblings & $0.02(0.01$ to 0.02$)$ & $0.02(0.01$ to 0.02$)$ \\
Parental smoking: cigarettes per day & $-0.07(-0.14$ to -0.01$)$ & $-0.03(-0.09$ to 0.04$)$ \\
& Odds ratio per year $(95 \%$ confidence interval) \\
Mother smoked in pregnancy with child & $1.01(0.99$ to 1.02$)$ & 1.01 (0.99 to 1.02$)$ \\
\hline
\end{tabular}

* Selected by year of birth as detailed in text.

Table 2 Unadjusted trends in outcome variables, and with adjustment for BMI SDS, from 1982 to 1994 in $9574+$ representative sample in boys aged 8 or 9 years ${ }^{\star}$ with information on symptoms and BMI

\begin{tabular}{|c|c|c|}
\hline \multirow[b]{2}{*}{ Variable } & \multicolumn{2}{|c|}{ Odds ratio per year ( $95 \%$ confidence interval) } \\
\hline & Unadjusted & Adjusted for BMI SDS \\
\hline Attacks of asthma & $1.09(1.07$ to 1.11$)$ & $1.09(1.07$ to 1.11$)$ \\
\hline Ever wheeze & $1.04(1.03$ to 1.06$)$ & $1.04(1.03$ to 1.06$)$ \\
\hline Persistent wheeze & $1.02(0.99$ to 1.05$)$ & $1.02(0.99$ to 1.05$)$ \\
\hline Attacks of bronchitis & $0.95(0.92$ to 0.98$)$ & $0.94(0.91$ to 0.97$)$ \\
\hline Asthma or bronchitis & 1.05 (1.02 to 1.07$)$ & $1.04(1.02$ to 1.07$)$ \\
\hline
\end{tabular}

«Selected by year of birth as detailed in text.

†Minimum number, with data for attacks of asthma and bronchitis and BMI.

Table 3 Unadjusted trends in outcome variables, and with adjustment for BMI SDS, from 1982 to 1994 in $8974+$ representative sample of girls aged 8 or 9 years ${ }^{\star}$ with information on symptoms and BMI

\begin{tabular}{|c|c|c|}
\hline \multirow[b]{2}{*}{ Variable } & \multicolumn{2}{|c|}{ Odds ratio per year ( $95 \%$ confidence interval) } \\
\hline & Unadjusted & Adjusted for BMI SDS \\
\hline Attacks of asthma & 1.09 (1.07 to 1.12$)$ & $1.09(1.05$ to 1.12$)$ \\
\hline Ever wheeze & 1.04 (1.02 to 1.05$)$ & $1.03(1.02$ to 1.05$)$ \\
\hline Persistent wheeze & $1.04(1.00$ to 1.07$)$ & $1.04(1.00$ to 1.07$)$ \\
\hline Attacks of bronchitis & $0.94(0.91$ to 0.98$)$ & $0.94(0.91$ to 0.98$)$ \\
\hline Asthma or bronchitis & $1.04(1.01$ to 1.07$)$ & $1.04(1.01$ to 1.07$)$ \\
\hline
\end{tabular}

$\star$ Selected by year of birth as detailed in text.

†Minimum number, with data for attacks of asthma and bronchitis and BMI

Table 4 Trends in selected outcome variables and in body mass index (BMI) and triceps skinfold thickness from 1983 to 1993 in an English inner city sample of children aged 8 or 9 years ${ }^{\star}$ with information on symptoms and BMI, adjusted for ethnic group

\begin{tabular}{llc}
\hline \multirow{2}{*}{ Variable } & Boys $(n=4474) t$ & Girls $(n=4509) t$ \\
\cline { 2 - 3 } & Odds ratio per year $(95 \%$ confidence interval) \\
\hline Attacks of asthma & $1.06(1.02$ to 1.10$)$ & $1.08(1.04$ to 1.13$)$ \\
Ever wheeze & $1.02(0.99$ to 1.04$)$ & $1.02(0.99$ to 1.04$)$ \\
Persistent wheeze & $1.00(0.97$ to 1.04$)$ & $1.02(0.98$ to 1.06$)$ \\
Attacks of bronchitis & $0.94(0.90$ to 0.99$)$ & $0.94(0.89$ to 0.99$)$ \\
Asthma or bronchitis & $1.01(0.97$ to 1.04$)$ & $1.01(0.97$ to 1.05$)$ \\
Body mass index SDS & Linear increase per year $(95 \%$ confidence interval) \\
Triceps skinfold SDS & $0.013(0.003$ to 0.023$)$ & $0.013(0.003$ to 0.022$)$ \\
& $0.000(-0.008$ to 0.009$)$ & $0.005(-0.003$ to 0.014$)$ \\
\hline
\end{tabular}

* Selected by year of birth as detailed in text.

†Minimum number, with data for attacks of asthma and bronchitis and BMI.

The response rate to the questionnaire ranged from $84 \%$ to $96 \%$ in the representative sample and from $78 \%$ to $83 \%$ in the inner city sample.

The trends in asthma and wheeze and in BMI are shown in fig 1 for all white boys in the representative sample (about 3600 children per year of survey from 1973 to 1982 and 5000 from 1984 to 1994). Although a trend in asthma symptoms was detected before 1982, a greater increase in asthma, ever wheeze, and BMI took place from 1982 onwards. A similar pattern was seen for girls in the representative sample.
As the potential for BMI to explain the trend in asthma was from 1982 onwards, the inner city sample was surveyed from 1983, and not all data were collected for the potential confounding variables in the earlier period, all formal analyses were carried out on the 1982-94 data.

Trends in potential explanatory variables are shown for the representative sample in table 1. There was a highly statistically significant $(p<0.001)$ increase in BMI in both boys and girls. Triceps skinfold thickness showed a positive trend in both sexes $(p<0.001$ and $p=0.003$, respectively). Family size increased slightly, as measured either by total number of siblings or number of older siblings. Birth weight showed a significant change only in girls after adjusting for gestational age. Parental smoking showed a small decline in total number of cigarettes smoked at home, which was statistically significant for boys, but there was no evidence for a change in mother smoking in pregnancy.

Trends in asthma, bronchitis, and symptoms are shown for the representative sample in tables 2 and 3. The unadjusted odds ratios show that there were increasing trends in all outcomes except for attack(s) of bronchitis, which showed a decrease in both boys (table 2) and girls (table 3). When "at least one attack of asthma or bronchitis" was analysed there was a positive trend which was statistically significant for both sexes. The BMI adjusted odds ratios and their $95 \%$ confidence intervals differ from the corresponding unadjusted estimates by 0.01 at most. Adjusting for BMI divided into categories of underweight, normal, overweight, and obese gave similar estimates. Adjustment for other variables in table 1 , whether singly or in combination, also had no detectable effect on the odds ratios for trend.

Table 4 shows trends in asthma, wheeze, bronchitis, BMI, and triceps skinfold SDS in the English inner city sample, with adjustment for ethnic group. Attacks of asthma showed a significant increase in both boys and girls, and bronchitis a significant decrease, but no statistically significant trend was seen in the other outcome variables. BMI SDS increased in both boys and girls but neither trend in triceps skinfold SDS was statistically significant. The trends in asthma were unchanged on adjusting for BMI SDS. Trends in BMI and asthma were inconsistent when examined by the four categories of ethnic group (not shown).

Table 5 shows the odds ratio for asthma in underweight, overweight, and obese children compared with normal weight children in the representative sample in 1982 and 1994, with adjustment for age. In 1982 there was a statistically significant variation in the odds ratio in boys $(p=0.007)$ but no linear trend and no relation of asthma to BMI in girls, while in 1994 there was a greater prevalence of asthma attacks in obese boys and girls than in children of normal weight and statistically significant trends with BMI SDS. However, no statistically significant interaction was found between BMI SDS and year. A similar test of interaction between asthma and BMI categories across all 
Table 5 Odds ratio, adjusted for age, for asthma in underweight, overweight and obese children in the representative sample compared with children of normal weight aged 4-11 years in 1982 and 1994

\begin{tabular}{|c|c|c|c|c|}
\hline & \multicolumn{2}{|l|}{ Boys } & \multicolumn{2}{|l|}{ Girls } \\
\hline & $n$ & Odds ratio $(95 \%$ CI) & $n$ & Odds ratio $(95 \% \mathrm{CI})$ \\
\hline \multicolumn{5}{|l|}{1982} \\
\hline Total & 3458 & & 3282 & \\
\hline Underweight & 767 & $1.66(1.12$ to 2.46$)$ & 1100 & $1.17(0.75$ to 1.84$)$ \\
\hline Normal weight (reference) & 2349 & 1.00 & 1888 & 1.00 \\
\hline Overweight & 799 & $2.15(1.30$ to 3.58$)$ & 255 & $0.90(0.38$ to 2.13$)$ \\
\hline Obese & 43 & $1.48(0.35$ to 6.22$)$ & 39 & $1.00(0.13$ to 7.44$)$ \\
\hline $\mathrm{p}$ value for trend with BMI SDS & & 0.76 & & 0.69 \\
\hline \multicolumn{5}{|l|}{1994} \\
\hline Total & 4778 & & 4578 & \\
\hline Underweight & 965 & $0.99(0.78$ to 1.25$)$ & 1277 & $0.83(0.63$ to 1.10$)$ \\
\hline Normal weight & 3110 & 1.00 & 2633 & 1.00 \\
\hline Overweight & 573 & $1.22(0.93$ to 1.59$)$ & 554 & $0.95(0.66$ to 1.37$)$ \\
\hline Obese & 130 & $1.79(1.12$ to 2.85$)$ & 114 & $2.27(1.33$ to 3.88$)$ \\
\hline $\mathrm{p}$ value for trend with BMI SDS & & 0.003 & & 0.011 \\
\hline $\mathrm{p}$ value for BMI SDS/year interaction & & 0.32 & & 0.15 \\
\hline
\end{tabular}

years in the cohorts aged 8 or 9 years was statistically significant for boys $(p=0.01)$ but not for girls $(\mathrm{p}=0.54)$.

Table 6 shows the 4 year incidence of asthma and "ever wheeze" in children free of asthma attacks or wheeze, respectively, at age 5 or 6 years in the representative samples. There was a clear trend of increasing incidence of both asthma and wheeze with increased BMI in both boys and girls. Although the numbers of obese children were small, there was a substantially increased risk of asthma or wheeze in these children compared with children of normal weight.

\section{Discussion}

The primary aim of this paper was to investigate whether the increase in BMI could explain the increase in asthma, as has been suggested. ${ }^{568}$ As far as we are aware, this is the first such analysis. The results show clearly that the increase in BMI cannot explain the increase in asthma. Given that the NSHG data showed a cross sectional relation between BMI and asthma, ${ }^{15}$ and trends in asthma ${ }^{910}$ and $\mathrm{BMI}^{13}{ }^{14}$ have previously been reported, this finding is surprising and at first sight contradictory. However, adjustment of the trends in asthma and symptoms by BMI assumes a constant relation of outcome to BMI SDS or BMI categories over time, and our results suggest that this was not the case.
Added evidence that the association between asthma and BMI is recent is provided by a contrast with results from the British 1958 birth cohort for the children at age 11 years. ${ }^{28}$ The only statistically significant difference found was that children with frequent current attacks of asthma and/or wheezy bronchitis had lower mean relative weight than other children. Indirect evidence for the positive association between asthma and BMI being recent is provided by the recent surge in interest in the topic which is not due to previous failure to investigate. ${ }^{29}$ Diagnostic shift cannot explain the whole of the rise in asthma as "asthma or bronchitis" also showed an increase.

A direct causal link between increased BMI per se and asthma now seems unlikely, firstly because the evidence suggests that it is a recent phenomenon, and secondly because the association is inconsistent in boys and girls in some groups. ${ }^{15}$ While possible mechanisms have been suggested for sex differences, ${ }^{26}$ none of those proposed can explain the sex difference in inner city children in England. ${ }^{15}$ The study in adults ${ }^{5}$ that showed obesity to precede the onset of asthma has been taken as evidence in favour of causality, ${ }^{8}$ and the comparable findings here might add to this view. However, if obesity is now a marker of a lifestyle or dietary risk factor for asthma that takes time to produce symptoms, an increased incidence in obese children or adults would be observed.

Table 6 Incidence and odds ratio for asthma or "ever wheeze" at 9 or 10 years of age in relation to normal weight children at 5 or 6 years of age in children symptom free at 5 or 6 years of age in the representative sample, 1982-94

\begin{tabular}{|c|c|c|c|c|}
\hline \multirow[b]{2}{*}{ BMI at age 5 or 6 (n, boys/girls) } & \multicolumn{2}{|l|}{ Boys } & \multicolumn{2}{|l|}{ Girls } \\
\hline & $\%$ & $\begin{array}{l}\text { Odds ratio }(95 \% \text { CI) compared } \\
\text { with normal weight }\end{array}$ & $\%$ & $\begin{array}{l}\text { Odds ratio ( } 95 \% \text { CI) compared with } \\
\text { normal weight }\end{array}$ \\
\hline \multicolumn{5}{|l|}{ Asthma } \\
\hline Underweight $(\mathrm{n}=756 / 958)$ & 4.5 & $0.87(0.59$ to 1.28$)$ & 2.8 & $0.92(0.58$ to 1.45$)$ \\
\hline Normal weight $(n=2332 / 2093)$ & 5.1 & 1.00 & 3.1 & 1.00 \\
\hline Overweight $(n=283 / 243)$ & 5.7 & $1.10(0.65$ to 1.89$)$ & 4.5 & $1.50(0.78$ to 2.89$)$ \\
\hline Obese $(n=44 / 35)$ & 20.5 & $4.74(2.23$ to 10.09$)$ & 11.4 & $4.09(1.40$ to 11.93$)$ \\
\hline $\mathrm{p}$ value between groups & & 0.0005 & & 0.037 \\
\hline \multicolumn{5}{|l|}{ Ever wheeze } \\
\hline Underweight $(n=682 / 902)$ & 6.6 & $0.92(0.65$ to 1.30$)$ & 4.3 & $0.96(0.65$ to 1.40$)$ \\
\hline Normal weight $(n=2084 / 1948)$ & 7.1 & 1.00 & 4.5 & 1.00 \\
\hline Overweight $(n=250 / 217)$ & 8.8 & $1.25(0.78$ to 2.00$)$ & 6.5 & $1.46(0.81$ to 2.61$)$ \\
\hline Obese $(n=38 / 16)$ & 23.7 & $4.03(1.87$ to 8.67$)$ & 12.5 & $4.70(1.89$ to 11.67$)$ \\
\hline $\mathrm{p}$ value between groups & & 0.0027 & & 0.005 \\
\hline
\end{tabular}


The incidence studies do, however, make reverse causality a less likely explanation. In favour of direct causality is the small randomised controlled trial of weight reduction in obese (BMI 30-48) asthmatic subjects. ${ }^{7}$ However, the asthmatic subjects randomised to the intervention group received a "very low energy dietary preparation" which "contained daily allowance of all essential nutrients". Thus, the intervention group may have experienced a diet more balanced than their usual one as well as weight reduction.

An alternative explanation for reports of the association being recent is that only with sufficient prevalence of obesity or a very large sample is a statistically significant association likely to be found. Although this could explain the evidence in the UK, it is harder to explain the lack of earlier reports from the USA where trends were more substantial before $1982,{ }^{30}$ and the mean BMI from NHANES I and II showed that before 1980 girls were already of a comparable weight to those in the UK in $1990 .^{31}$

Obesity is associated with dyspnoea on exercise $^{2}$ which could account for part of the cross sectional association between reported wheeze and obesity, but this could be expected to be consistent over time. Our results therefore suggest that this is at most only a small part of the explanation for the association.

Although the NSHG provided no evidence for a contribution of any of the other variables studied to the increase in asthma, we cannot rule these out totally as birth weight, length of gestation, and parental smoking were selfreported, usually by the mother. However, they cannot explain the association between asthma and BMI, or why the trend in BMI does not account for any of that in asthma. Family size increased slightly from 1982 to 1994 but decreased in the earlier period of the study when the trend in asthma was lower. Adjustment for social class (not shown) did not change any of the findings, unsurprisingly for the main results as there has been no appreciable trend in social class distribution.

Among possible explanations for the association that are compatible with the various findings are lifestyle differences between obese and non-obese subjects that have recently emerged or become more marked. Camargo et al suggested that obese individuals may have greater exposure to indoor allergens than subjects of normal weight because they spend more time indoors or that there might be dietary differences between the groups. They found no evidence that differences in nutrient intake could explain the association. However, both diet, especially micronutrient intake, and activity levels are difficult to measure, and this possibility remains.

Among other factors that may have changed over time, possibly differentially between overweight and normal weight children, are participation in sport within and outside school and control of food intake, either through increased choice at school lunch or through increased pocket money spent on food. Unfortunately, in the UK data on these factors are either non-existent or lacking in consistency over the time frame studied here.

The suggestion that the increase in obesity could explain the increase in asthma was a simple hypothesis that had temporal plausibility. The NSHG data provide strong evidence against this hypothesis while confirming an association between asthma and obesity which seems to have arisen relatively recently. Surveys which include diet and physical activity may suggest an explanation for the association which is unlikely to be directly causal.

Susan Chinn and Roberto Rona are currently funded by the Higher Education Funding Council for England. The National Higher Education Funding Council for England. The National
Study of Health and Growth was funded by the Department of Study of Health and Growth was funded by the Department of
Health for England and Wales and the Scottish Home and Health for England
Health Department.

1 Shaheen SO, Sterne JAC, Montgomery SM, et al. Birth weight, body mass index and asthma in adults. Thorax 1999;54:396-402

2 Chen Y, Dales R, Krewski D, et al. Increased effects of smoking and obesity on asthma among female Canadians: the national population health survey, 1994-1995. Am ff Epidemiol 1999;150:255-62.

3 Luder E, Melnik TA, DiMaio M. Association of being overweight with greater asthma symptoms in inner city black and Hispanic children. F Pediatr 1998;132:699-703.

4 Gennuso J, Epstein LH, Paluch RA, et al. The relationship between asthma and obesity in urban minority children and adolescents. Arch Pediatr Adolesc Med 1998;152:1197200.

5 Camargo CA Jr, Weiss ST, Zhang S, et al. Prospective study of body mass index, weight change, and risk of adult-onset asthma in women. Arch Intern Med 1999;159:2513-4.

6 Castro-Rodriguez JA, Holberg CJ, Morgan WJ, et al. Increased incidence of asthmalike symptoms in girls who become overweight or obese during the school years. $\mathrm{Am} \mathcal{F}$ Respir Crit Care Med 2001;163:1344-9.

7 Stenius-Aarniala B, Poussa T, Kvarnström J, et al. Immediate and long term effects of weight reduction in obese people with asthma: randomised controlled study. $B M F$ 2000;320:827-32.

8 Shaheen SO. Obesity and asthma: cause for concern? Clin Exp Allergy 1999;29:291-3.

9 Burney PGJ, Chinn S, Rona RJ. Has asthma prevalence increased in children? Evidence from the national study of health and growth 1973-86. BMF 1990;300:1306-10.

10 Rona RJ, Chinn S, Burney PGJ. Trends in the prevalence of asthma in Scottish and English primary school children 1982-1992. Thorax 1995;50:992-3.

11 Burr ML, Butland BK, King S, et al. Changes in asthma prevalence: two surveys 15 years apart. Arch Dis Child 1989;64:1452-6.

12 Anderson HR, Butland BK, Strachan DP. Trends in prevalence and severity of childhood asthma. BMF 1994;308: lence and

13 Hughes JH, Li L, Chinn S, et al. Trends in growth in England and Scotland 1972 to 1994. Arch Dis Child 1997; 76:182-9.

14 Chinn S, Hughes J, Rona R. Trends in growth and obesity in ethnic groups in Britain. Arch Dis Child 1998;78:513-7.

5 Figueroa-Muñoz JI, Chinn S, Rona RJ. Association between obesity and asthma in 4 to 11 year old children in the UK. Thorax 2001;56:133-7.

16 Crane J, Pearce N, Shaw R, et al. Asthma and having children. BMF 1994;309:272.

17 Rona R J, Hughes JM, Chinn S. The association between asthma and family size between 1977 and 1994. F Epidemiol Community Health 1999;53:15-19

18 Schwartz J, Gold D, Dockery DW, et al. Predictors of asthma and persistent wheeze in a national sample of children in the United States. Association with social class, perinatal events, and race. Am Rev Respir Dis 1990;142: perinatal

19 Leadbitter P, Pearce N, Cheng S, et al. Relationship between fetal growth and the development of asthma and atopy in childhood. Thorax 1999;54:905-10.

20 Rona RJ, Chinn S. National study of health and growth: social and biological factors associated with height of children from ethnic groups living in England. Ann Hum Biol 1986;13:453-71

21 Rona RJ, Altman, DG. National study of health and growth: standards of attained height, weight and triceps skinfold in English children 5 to 11 years old. Ann Hum Biol 1977;4:501-23.

22 Tanner JM, Whitehouse RH, Takaishi M. Standards from birth to maturity for height, weight, height velocity, and weight velocity: British children, 1965. Arch Dis Child 1966;41:454-71, 613-35.

23 Child Growth Foundation. BMI charts. UK cross-sectional reference data: 1990/1. Available from Child Growth Foundation, 2 Mayfield Avenue, London W4 1PW. 
24 Tanner JM, Whitehouse RH. Standards for subcutaneous fat in British children. Percentiles for thickness of skinfolds over triceps and below scapula. BMF 1962;1:446-50.

25 Cole TJ, Freeman JV, Preece MA. Body mass index reference curves for the UK Arch Dis Child 1995;73:25-9.

26 Bland JM, Peacock JL, Anderson HR, et al. The adjustmen of birthweight for very early gestational ages: two related problems in statistical analysis. Appl Stat 1990;39:229-39. 27 Clayton D, Hills M. Statistical models in epidemiology. Oxford: Oxford University Press, 1993: 99-100, 229-233.

28 Peckham C, Butler N. A national study of asthma in childhood. F Epidemiol Community Health 1978;32:79-85.
29 Somerville SM, Rona RJ, Chinn S. Obesity and respiratory symptoms in primary school. Arch Dis Child 1984;59:940-

30 Troiano RP, Flegal KM, Kuczmarski RJ, et al. Overweight prevalence and trends for children and adolescents. The National Health and Nutrition Surveys. Arch Pediatr Adolesc Med 1995;149:1085-91.

31 Campaigne BN, Morrison JA, Schuman BC, et al. Indexes of obesity and comparison with previous national survey data in 9- and 10-year-old black and white girls: the National heart, Lung, and Blood Institute Growth and Health Study. $\mathcal{F}$ Pediatr 1994;124:675-80. 